\title{
THE ANTIBACTERIAL EFFECT OF A DIODE LASER USED AS AN ADJUNCT IRRIGANT ON CLINICAL ISOLATE OF ENTEROCOCCUS FAECALIS BIOFILM (IN VITRO)
}

\author{
AYU SANDINI, RATNA MEIDYAWATI*, KAMIZAR, DEWA AYU NPA
}

\author{
Department of Conservative Dentistry, Faculty of Dentistry, Universitas Indonesia, Jakarta, Indonesia. Email: meidyawati58@gmail.com
}

Received: 16 September 2017, Revised and Accepted: 3 October 2017

\section{ABSTRACT}

Objective: The elimination of bacteria from the root canal has always been a problem in root canal management, and Enterococcus faecalis often found in the persistent intraradicular infections that occur after poor or unsuccessful endodontic treatments. The use of an irrigant with a diode laser adjunct eliminates this bacteria.

To analyze and compare the effectiveness of a diode laser, chlorhexidine $2 \%$, and natrium hypochlorite $2.5 \%$ on a clinical isolate of $E$. faecalis biofilms.

Methods: Using E. faecalis biofilms from clinical isolate were grown on microtiter well plate, incubated for $24 \mathrm{~h}$ and subjected to the following treatments: Natrium hypochlorite 2.5\% (5 s), chlorhexidine 2\% (5 s), natrium chloride 0.9\% (5 s), and the irrigants with additional diode laser irradiation ( $980 \mathrm{~nm}, 15 \mathrm{~Hz}, 1.5 \mathrm{~W}, 3.5 \mathrm{~J}, 5 \mathrm{~s}$ ). The antibacterial effects of the irrigants and diode laser were scored using colony form units (CFU).

Results: The clinical isolate colony of E. faecalis that was exposed to a saline solution and diode laser application had the highest score ( $18700 \mathrm{CFU} / \mathrm{ml})$, while the lowest score $(80,00 \mathrm{CFU} / \mathrm{ml})$ was recorded in the group that was exposed to a chlorhexidine $2 \%$ irrigant with additional diode laser application.

Conclusion: The diode laser had an antibacterial effect on a clinical isolate of E. faecalis biofilm, and this effect was increased when it was used in addition to the application of chlorhexidine $2 \%$ and natrium hypochlorite $2.5 \%$ irrigants.

Keywords: Enterococcus faecalis, Diode laser, Chlorhexidine 2\%, Natrium hypochlorite 2.5\%.

(c) 2017 The Authors. Published by Innovare Academic Sciences Pvt Ltd. This is an open access article under the CC BY license (http://creativecommons. org/licenses/by/4. 0/) DOI: http://dx.doi.org/10.22159/ijap.2017.v9s2.25

\section{INTRODUCTION}

The primary goal of endodontic treatment is to eliminate polymicrobial infection, which is the main cause of periapical disease. There are up to 40 isolated species of bacteria present in the root canal [1,2]. Cocci, rod, filament, and anaerobic facultative bacteria are the most commonly identified microbes in primary endodontic infection [3]. These microorganisms are found suspended in the main root canal or attached to the wall of the root canal; some have even been found inside the dentine tubules. Failure to eliminate these bacteria from the root canal is the main cause of unsuccessful endodontic treatments, which can lead to further infection of the periapical tissue.

Enterococcus faecalis is often found in persistent endodontic infections, where it is the most difficult bacteria to eliminate due to its numerous virulence factor genes. In an in vitro test of 50 teeth that had undergone root canal treatment, Zoletti et al. found that $80 \%$ were infected by E. faecalis [4]. In addition, Wang et al. observed an E. faecalis infection in $38 \%$ of the 58 teeth with poor root canal treatments that they studied and noted a higher prevalence in teeth with poor obturation [5].

Periapical disease can be prevented or cured with an endodontic triad that consists of access opening, root canal preparation, and complete obturation of the canal space [6]. The best method to clean and shape the root canal remains the subject of considerable debate: Although there are different concepts and strategies for root canal preparation, there is mutual agreement on a chemomechanical preparation that combines a chemical irrigant with a mechanical debridement using hand or rotary instruments [7].

The most important step in the elimination of bacteria from the canal space is the mechanical preparation of the root canal. Byström and Sundqvist (1981) documented the bacterial count before and after a mechanical preparation that did not make use of an irrigant or medication, finding that the count had decreased to $10^{2}-10^{3}$. However, after five visits without antibacterial medication, the count had increased by 50\% [8]. Peters et al. (2001) found that mechanical preparation left more than $35 \%$ of the canal space uncleared, which could lead to the failed elimination of bacteria from the root canal [9]. Antibacterial medication is needed because it eliminates these bacteria. Bystrom and Sunqvist found that the use of an irrigant in addition to mechanical preparation lowered the bacterial count to $40-60 \%$ [8].

The irrigation works in direct contact with the target and, to a limited extent, penetrates the root canal wall. Paque (2009) reported that areas remained unaffected after mechanical instrumentation using either rotary instruments or manual techniques [10]. The irrigant was therefore unable to reach and eliminate microorganisms from the inner side of the dentine layer [11] This is the reason that a combination of a disinfectant solution with a supplementary irrigant is used $[12,13]$.

Numerous antibacterial irrigants can be used in endodontics. A combination of chlorhexidine (CHX) and natrium hypochlorite $(\mathrm{NaOCl})$ is the most commonly used endodontic treatment and is considered the golden standard. The first, CHX, is a wide-spectrum antibacterial agent that works on a lot of microorganisms, including E. faecalis [14]. It is also recommended due to its substantivity, which leads to a longer therapeutic effect. However, Mistry et al. (2012) found CHX to be cytotoxic in direct contact with human cells [7]

As endodontic technology has developed, research has been conducted on instruments and techniques with the ultimate goal of shortening working times and improving the effectiveness of root canal treatment. 
One of the latest technological innovations has been the use of lasers as supplementary tools to disinfect the root canal. A laser is a device that emits a monochromatic and coherent light. This high-intensity beam is effective and shortens the duration of root canal sterilization procedures. The laser's antibacterial effect depends on the amount of heat that the device generates [13-15].

Lasers were first used in endodontic treatment procedures in 1980, and their use has expanded ever since. Diode lasers are the most commonly used lasers in dentistry [16]. With wavelengths of $810 \mathrm{~nm}$ and $980 \mathrm{~nm}$, diode lasers have a fiber diameter range of 200-600 $\mu \mathrm{m}$. SchulteLünzum et al. demonstrated that a 980-nm-wavelength diode laser could eliminate bacteria from the inside of the canal space and even from deep inside the dentine tubules [17]. Benedicenti et al. (2008) found that the use of a diode laser in addition to a conventional endodontic treatment increased the success rate of the treatment in vitro and significantly lowered contamination in the canal space. A diode laser is the primary choice because it is relatively more economical than other lasers and is easy to both use and transport [12-15].

The present study used standardized bacteria samples collected by previous researchers from non vital teeth with the periapical disease, which was taken from patients at the dental conservation clinic of Rumah Sakit Khusus Gigi Dan Mulut-Fakultas Kedokteran Gigi Universitas Indonesia (RSGMP FKG UI) [12]. The E. faecalis bacteria from the clinical isolate were considered more persistent than the standardized American Type Culture Collection (ATCC) bacteria because they came directly from the root canal and had higher survival ability and virulence factors. Conversely, ATCC bacteria were cultured in a controlled environment with specific nutrients specifically provided.

The goal of this research was to analyze and compare the antibacterial effect of a diode laser when used as an adjunct irrigant on a clinical isolate of E. faecalis biofilm.

\section{METHODS}

This research was conducted in the Oral Biology Laboratory of the Faculty of Dentistry at the University of Indonesia, from October to November, 2016.

E. faecalis biofilms from clinical isolate were grown on microtiter well plate, incubated for $24 \mathrm{~h}$ and subjected to the following treatments: $\mathrm{NaOCl} 2.5 \%$ (5 s), chlorhexidine 2\% (5 s), natruim chloride 0,9\% (5 s), and the irrigants with additional diode laser irradiation $(980 \mathrm{~nm}, 15 \mathrm{~Hz}$, $1.5 \mathrm{~W}, 3.5 \mathrm{~J}, 5 \mathrm{~s}$ ).

Colony form unit (CFU) scoring was used to acquire the antibacterial effectiveness of all testing material. Live and colonized E. faecalis bacteria on BHIA preparation were manually counted after being exposed to the testing material. Each testing material's antibacterial effectiveness was assessed by observing the number of colonies formed: A high $\mathrm{CFU} / \mathrm{ml}$ score, for example, indicated a lower antibacterial effect.

The data were processed with SPSS 20.0 software. The Shapiro-Wilk test was used to test normality because the sample was $<50$. After assessing that the data were distributed normally ( $p>0.05)$, a homogeneity test was performed, which found that the data were not homogenic $(\mathrm{p}<0.05)$; therefore, a Tamhane post-hoc test was conducted.

\section{RESULTS}

The highest E. faecalis CFU score (18700 CFU/ml) was observed in the clinical isolate colony that had been exposed to a saline solution and a diode laser (Table 1). Conversely, the lowest average score (8000 CFU/ $\mathrm{ml}$ ) was recorded in the group of CHX $2 \%$ with additional diode laser application. This demonstrated that the best antibacterial effect was obtained by the CHX $2 \%$ irrigant with additional diode laser application.
A statistically significant difference $(\mathrm{p}=0.042)$ between the CFU scores of the E. faecalis biofilm group and the saline with additional diode laser application group was found through post-hoc analysis (Table 2). Furthermore, a statistically significant difference $(\mathrm{p}<0.01)$ was also observed between the saline with additional diode laser application group and the CHX $2 \%$ with additional diode laser application group.

A statistically significant $(\mathrm{p}=0.021)$ difference to the CFU score was noted when Group 2 ( $\mathrm{NaOCl} 2.5 \%$ without diode laser) was compared to Group 5 ( $\mathrm{NaOCl} 2.5 \%$ with diode laser). Similarly, a statistically significant $(\mathrm{p}=0.0)$ difference was observed between the CFU scores of Groups 3 (CHX 2\%) and 6 (CHX 2\% with diode laser). However, CFU scores of Groups 2 ( $\mathrm{NaOCl} 2.5 \%)$ and 3 (CHX 2\%) did not exhibit a statistically significant difference $(\mathrm{p}=0.133)$.

\section{DISCUSSION}

This study was conducted to analyze the antibacterial effect of diode lasers on a clinical isolate of E. faecalis biofilm. This specific bacterium was chosen because it is often found in poor and unsuccessful endodontic treatments and is highly resistant against different kinds of endodontic treatment. In this study, samples of standardized clinical isolate bacteria taken by previous researchers from non vital teeth with the periapical disease at the dental conservation clinic (RSGM FKG UI) were used [12]. A clinical isolate of $E$. faecalis bacteria was considered more persistent than ATCC bacteria because it came from the root canal space of tooth with the periapical disease. This gave it high survival ability and virulence compared to the ATCC bacteria, which were cultured in a controlled environment and provided with specific nutrition.

One of the obstacles to the elimination of E. faecalisis its ability to form a biofilm inside the canal space. Huang et al. (2007) found that biofilm bacteria are more difficult to incinerate than their planktonic forms [18] Biofilm is a complex aggregation of multiple microorganisms that secrete a protective and adhesive exopolymeric matrix, which is called an extracellular polymeric substance (ESP) or exopolysaccharide. Negatively charged exopolysaccharides act as physical and mechanical barriers that prevent the antibacterial agent from penetrating the biofilm structure [19].

Numerous techniques are used to form biofilm in vitro. In this study, a well plate was used as the growth medium for the biofilm. The well plate's pedestal was flat and identical to the letters V, C, and U. The use of these plates provided uniformity on a pedestal and compatible surface for the biofilm to form. The length and diameter of the tubes were designed to shorten the working time for placement of sample, and the plate's lid was used to avoid possible contamination and evaporation during the incubation process.

This study used $\mathrm{NaOCl} 2.5 \%$ and $\mathrm{CHX} 2 \%$ as testing materials because they are commonly used as irrigants and considered the golden standard for canal space disinfection. Gomes (2002) concluded that $\mathrm{NaOCl} 2.5 \%$ had an antibacterial effect on E. faecalis by transforming fatty acid on the bacteria wall to fatty acid salts and glycerol, thereby destroying the wall of the cell. Stuart et al. found that CHX 2\% was very effective at eliminating $E$. faecalis: The positive pole of the CHX molecule bonded with the phospholipid and the negative charge of the lipopolysaccharide on the bacterial membrane, which changed the osmotic balance and lowered the integrity of the cell wall. This increased the cell wall's permeability, allowing the CHX to enter and cause the bacteria's cytoplasm to precipitate and coagulate. Thereby eliminating the bacteria.

The results of this study are displayed in Table 1 . All groups showed decreasing CFU scores compared to the non-treatment group, which demonstrated that all of the testing materials used in this study had an antibacterial effect on the clinical isolate of the E. faecalis biofilm. The group with saline and additional diode laser had the lowest CFU score, 
Table 1: Average scoring of antibacterial effect on clinical isolate of $E$. faecalis biofilm (CFU/ml)

\begin{tabular}{|c|c|c|c|c|}
\hline \multirow[t]{2}{*}{ Research group } & \multirow[t]{2}{*}{ n } & \multirow[t]{2}{*}{ Average score \pm SD } & \multicolumn{2}{|l|}{$95 \%$ IK } \\
\hline & & & Lower limit & Upper limit \\
\hline E. faecalis biofilm & 3 & $227.33 \pm 6.429$ & 220 & 232 \\
\hline Ktf CHX 2\% & 3 & $153.67 \pm 1.528$ & 152 & 153 \\
\hline Saline + diode laser & 3 & $187.00 \pm 3.000$ & 184 & 190 \\
\hline $\mathrm{NaOCl} 2.5 \%$ + diode laser & 3 & $134 \pm 1.000$ & 133 & 135 \\
\hline CHX $2 \%$ + diode laser & 3 & $80.00 \pm 2.646$ & 78 & 83 \\
\hline
\end{tabular}

E. faecalis: Enterococcus faecalis, CFU: Colony form units, SD: Standard deviation, CHX: Chlorhexidine

Table 2: Substantial scoring of antibacterial effect on $\boldsymbol{E}$. faecalis bioflim, NaOCl 2.5\%, CHX $2 \%$ group and additional diode laser application group

\begin{tabular}{ll}
\hline Research group & p-score \\
\hline E. faecalis biofilm versus saline+diode laser & 0.042 \\
NaOCl 2.5\% versus CHX 2\% & 0.133 \\
NaOCl 2.5\% versus NaOCl 2.5\% + diode laser & 0.021 \\
CHX 2\% versus CHX 2\% + diode laser & 0.000 \\
NaOCl 2.5\% + diode laser versus CHX 2\% + diode laser & 0.003 \\
Saline+diode laser versus CHX 2\% + diode laser & 0.000 \\
\hline
\end{tabular}

Tamhane's post-hoc test, with substantial scoring of $\mathrm{p}<0.05$,

E. faecalis: Enterococcus faecalis, CHX: Chlorhexidine

which showed that the diode laser itself had an antibacterial effect on E. faecalis biofilm even when used without a bactericidal irrigant.

The results of this study agreed with Benedicenti et al. (2008), Schulte-Lünzum et al., and Moritz et al., who each found that diode lasers were able to eliminate E. faecalis bacteria in biofilm. While no certain references describe the laser's mechanism against E. faecalis, Moritz et al. observed a reaction between the ions emitted by the laser and molecules on the cell wall. This reaction destroyed the protein molecules in the cell wall, which ultimately disrupted the bacterial cell membrane. Even the smallest membrane disruption causes a great transformation of the bacteria [20]. In addition, the thermal effect of the laser beam is also believed to disrupt the cell membrane by increasing its temperature by $42-52^{\circ} \mathrm{C}$ over its normal temperature of $37^{\circ} \mathrm{C}$. At this temperature, the biomolecular changes, which causes a significant transformation of the membrane [10-21].

This study found no substantial difference between the CFU scores for the $\mathrm{NaOCl} 2.5 \%$ and $\mathrm{CHX} 2 \%$ groups (Table 2). However, controversy remains as to which is better at eliminating E. faecalis: Our findings conflict with several similar studies conducted by Mainakandan et al., which found that $\mathrm{NaOCl} 2.5 \%$ had a better antibacterial effect than CHX 2\%. Conversely, O'hara et al. found that CHX $2 \%$ had a better antibacterial effect than $\mathrm{NaOCl} 2.5 \%$. The present study found a significant difference between the CFU scores of the CHX 2\% group and the CHX $2 \%$ with additional diode laser application group; namely, we found that the latter group's score was lower (Table 2). Even the average scoring on all the groups, the CHX $2 \%$ with the additional diode laser application group had the lowest average CFU score, which means that it exhibited the best antibacterial effect. This is consistent with Mithra et al. (2011), who compared the antibacterial effects of $\mathrm{NaOCl} 2.5 \%$, CHX 2\%, and MTAD irrigants combined with the use of a laser and found that the CHX $2 \%$ group had the best antibacterial effect. While there are still no references that describe the reaction between diode lasers and CHX 2\%, Moritz (2006) has argued that the laser beam could cause a transformation of the cell structure and bacterial molecule. Radiation from the laser beam acts as a bactericide by transforming and destroying the bacteria's cell wall. This occurs because CHX uses the positive ions from its biguanide content to bind with the negative ions of the protein molecules that form the bacteria's cell wall, which causes the lysis and osmotic disruption of the wall. Combined, the diode laser and CHX 2\% strengthen each other's antibacterial effects.

This study also found a significant difference between Groups 2 and 5 (the $\mathrm{NaOCl} 2.5 \%$ and $\mathrm{NaOCl} 2.5 \%$ with additional diode laser application groups, respectively). The CFU score of the $\mathrm{NaOCl} 2.5 \%$ with additional diode laser application group was lower than that of the $\mathrm{NaOCl} 2.5 \%$ group, which indicated that the diode laser increased the antibacterial effect of the $\mathrm{NaOCl} 2.5 \%$.

This is consistent with Neelakantan et al. (2015), who concluded that the use of a diode laser improved results for a $\mathrm{NaOCl} 2.5 \%$ irrigant. In addition, Pablo-Castelo et al. (2012) found that the combination of E. faecalis with a diode laser created a combined effort that maximized its antibacterial effect. This is caused not only by the combined antibacterial effect of the diode laser and $\mathrm{NaOCl} 2.5 \%$ but also by the thermal effect of the diode laser, which enhances the ability of the $\mathrm{NaOCl} 2.5 \%$ to eliminate E. faecalis.

\section{CONCLUSION}

Diode lasers had an antibacterial effect on a clinical isolate of $E$. faecalis biofilm. This antibacterial effect was increased when the diode laser was used in addition to $\mathrm{CHX} 2 \%$ and $\mathrm{NaOCl} 2.5 \%$ irrigants.

This was a preliminary study that used direct contact between E. faecalis bacteria and the tested materials. Further research that uses teeth as the bacterial culture medium and includes a larger sample is needed. In addition, more advanced research is required to simulate the clinical environment of the canal space using the required protocol based on clinical appearance to provide a clearer picture as to diode lasers' antibacterial effects in vivo.

\section{ACKNOWLEDGMENT}

This study was supported by the Directorate of Research and Community Engagement of the Universitas Indonesia.

The publication of this manuscript is supported by Universitas Indonesia.

\section{REFERENCES}

1. Di Filippo G, Sidhu SK, Chong BS. The role of biofilms in endodontic treatment failure. Endod Prac Today 2014;8:87-103

2. Guimarães DL, Otoch HM, Andrade CL, Ferreira CM, Rocha MM, Gomes FA. Microbiological evaluation of infected root canals and their correlation with pain. RSBO 2012;9:31-7.

3. Camargo AD. The antibacterial effects of lasers in endodontics. Roots 2012;31:8-14.

4. Zoletti GO, Carmo FL, Pereira EM, Rosado AS, Siqueira JF Jr, Santos KR. Comparison of endodontic bacterial community structures in root-canal-treated teeth with or without apical periodontitis. J Med Microbiol 2010;59:1360-4

5. Wang QQ, Zhang CF, Chu CH, Zhu XF. Prevalence of Enterococcus faecalis in saliva and filled root canals of teeth associated with apical periodontitis. Int J Oral Sci 2012;4:19-23

6. Akbar SM, Siti MS. Perawatan Saluran Akar: Buku Ilmu Endodontik. Mullana: Maharishi Markandeshwar University; 2009. 
7. Kandaswamy D, Venkateshbabu N. Root canal irrigants. J Conserv Dent 2010;13:256-64.

8. Byström A, Sundqvist G. Bacteriologic evaluation of the efficacy of mechanical root canal instrumentation in endodontic therapy. Scand $\mathbf{J}$ Dent Res 1981;89:321-8.

9. Yang G, Yuan G, Yun X, Zhou X, Liu B, Wu H. Effects of two nickeltitanium instrument systems, mtwo versus ProTaper universal, on root canal geometry assessed by micro-computed tomography. J Endod 2011;37:1412-6.

10. Bago I, Plecko V, Gabric Panduric D, Schauperl Z, Baraba A, Anic I. Antimicrobial efficacy of a high-power diode laser, photo-activated disinfection, conventional and sonic activated irrigation during root canal treatment. Int Endod J 2013;46:339-47.

11. Mehrvarzfar P, Saghiri MA, Asatourian A, Fekrazad R, Karamifar K, Eslami $\mathrm{G}$, et al. Additive effect of a diode laser on the antibacterial activity of $2.5 \% \mathrm{NaOCl}, 2 \% \mathrm{CHX}$ and MTAD against Enterococcus faecalis contaminating root canals: An in vitro study. J Oral Sci 2011;53:355-60.

12. Ayu NP, Bachtiar SM. Quantitave real-time PCR of cps Type 1,2 and 5 of Enterococcus faecalis and Candida albican isolated from infected root canal of subject requiring endodontic treatment. J Int Dent Med Res 2016;9:157-63.

13. Shajahan PA, Kumar PR, Hariprasad A, Mathew J, Shaji AP,
Ahammed MF. Lasers: The magic wand in esthetic dentistry!! J Int Oral Health 2015;7:119-21.

14. Banerjee S, Sreya P. Low level laser therapy (LLLT)-a boon to dentistry. Guident 2015;9:62-3.

15. Beer F, Buchmair A, Wernisch J, Georgopoulos A, Moritz A. Comparison of two diode lasers on bactericidity in root canals - An in vitro study. Lasers Med Sci 2012;27:361-4.

16. Coluzzi D, Convissar RR. Laser fundamentals. In: Convissar R, editor. Principles and Practice of Laser Dentistry. $2^{\text {nd }}$ ed. St. Louis: Elsevier; 2016.

17. Schulte-Lünzum R, Gutknecht N, Conrads G, Franzen R. The impact of a $940 \mathrm{~nm}$ diode laser with radial firing tip and bare end fiber tip on Enterococcus faecalis in the root canal wall dentin of bovine teeth: An in vitro study. Photomed Laser Surg 2017;35:357-63.

18. Siqueira JF Jr. Primary endodontic infection. In: Treatment of Endodontic Infections. London: Quintessence Publishing; 2011.

19. Sedgley CM, Lennan SL, Appelbe OK. Survival of Enterococcus faecalis in root canals ex vivo. Int Endod J 2005;38:735-42.

20. Moritz A, Schoop U. Lasers in endodontics. In: Oral Laser Application. Berlin: Quintessenz Verlags-Gmbh; 2006

21. Portenier I, Waltimo TM, Haapasalo M. Enterococcus faecalis-the root canal survivor and "star" in post-treatment disease. Endod Topics 2003;6:135-59. 